\title{
Analisis Tingkat Perkembangan Kawasan Agropolitan Desa Perpat Kabupaten Belitung Berbasis Komoditas Unggulan Ternak Sapi Potong
}

\author{
Analysis of Area Development of Perpat Agropolitan Village, District of Belitung \\ Based on Beef Cattle Commodities
}

\author{
Suyitman $^{1}$ dan S.H. Sutjahjo ${ }^{2}$ \\ ${ }^{1}$ Fakultas Peternakan Universitas Andalas, Kampus Limau Manis Padang, 25163 \\ ${ }^{2}$ Fakultas Pertanian Institut Pertanian Bogor, Kampus IPB Darmaga Bogor \\ e-mail: suyitman_psl@yahoo.co.id
}

(Diterima: 14 Maret 2011; Disetujui: 2 Mei 2011)

\begin{abstract}
This study aims to analyze the level of area development of Perpat Agropolitan Village - District of Belitung-Province of Bangka Belitung based on beef cattle commodity in terms of 5 (five) dimensions agropolitan level of area development, namely: the dimensions of agribusiness, agro-industry, marketing, infrastructure and superstructure. This study use a method of analysis of Multidimensional Scaling (MDS) called Rap-agrop and the results are expressed in index form and the status of sustainability. The result of $M D S$ analysis shows the level of development area of Perpat agropolitan village, based on beef cattle farm commodities, was still low, ie: including Pre Regions Agropolitan. This region has an index value of Rapagrop dimensional good enough for agribusiness (50.57\%), infrastructure (64.49\%), and the superstructure (57.23\%), while the dimensions of agro-industries (6.52\%) and marketing (9.98\%) had an index value that is poorly. The key factors that strongly affected the level of development of the region agropolitan Perpat-Belitung, namely: 1) the production of beef cattle and 2) the production of processed meat. To enhance the development of this area is to do a thorough improvement of all attributes that are sensitive, so that all dimensions in the region agropolitan Perpat become enhanced and more sustainable.
\end{abstract}

Keywords: agropolitan, beef cattle, sustainability index, Belitung district

\section{PENDAHULUAN}

Pengembangan kawasan agropolitan di Indonesia, yang diuji coba mulai tahun 2002 merupakan salah satu upaya dalam merealisasikan pembangunan ekonomi berbasis pertanian pada kawasan pertanian terpilih dengan pendekatan pertanian industri. Kawasan pertanian yang terpilih ini dapat merupakan kawasan atau sentra produksi pertanian berbasis tanaman pangan, hortikultura, perkebunan, perternakan atau komoditas campuran. Kawasan agropolitan adalah kawasan terpilih dari kawasan agribisnis atau sentra produksi pertanian terpilih, dimana pada kawasan tersebut terdapat Kota Pertanian (agropolis) yang merupakan pusat pelayanan agribisnis yang melayani, mendorong, dan memacu pembangunan pertanian kawasan dan wilayah-wilayah sekitarnya (Deptan, 2004; Moe, 2004). Pengembangan kawasan agropolitan adalah bertujuan meningkatkan pendapatan dan kesejahteraan masyarakat melalui percepatan pembangunan wilayah dan peningkatan keterkaitan desa dan kota dengan mendorong berkembangnya sistem dan usaha agribisnis yang berdaya saing. Sasaran pengembangan kawasan agropolitan adalah untuk mengembangkan kawasan pertanian yang berpotensi menjadi kawasan agropolitan, melalui: 1) pemberdayaan masyarakat pelaku agribisnis agar mampu meningkatkan produksi, produktivitas komoditi pertanian serta produk-produk olahan pertanian, yang dilakukan dengan pengembangan sistem dan usaha agribisnis yang efisien; 2) penguatan kelembagaan petani; 3) pengembangan kelembagaan agribisnis, seperti: penyedia agroinput, 
pengelolaan hasil, pemasaran, dan penyedia jasa; 4) pengembangan kelembagaan penyuluhan pembangunan terpadu; dan 5) pengembangan iklim yang kondusif bagi usaha dan investasi (Warner, 2002 dan Rustiadi et al., 2006).

Untuk menilai tingkat perkembangan kawasan agropolitan harus berdasarkan pada ukuran-ukuran ideal dimensi kawasan agropolitan yang meliputi dimensi agribisnis, agroindustri, pemasaran, infrastruktur, dan suprastruktur (Evans, 2006; Suyitman et al., 2009). Suatu kawasan tergolong menjadi kawasan agropolitan, jika kawasan tersebut sudah memiliki: 1) komoditas unggulan dan olahannya; 2) dapat menampung hasil dari kawasan agropolitan dan luar kawasan; 3) terdapat kelompok tani dan koperasi tani; 4) Kelembagaan Balai Penyuluh Pertanian (BPP) sebagai penyuluh agribisnis dan pembangunan; 5) sarana dan prasarana umum sudah memadai (Deptan, 2004).

Kawasan Agropolitan Desa Perpat terletak di Kecamatan Membalong, terletak di bagian Barat Daya Kabupaten Belitung, Provinsi Bangka Belitung dengan luas seluruhnya 909,55 ha yang meliputi 12 desa termasuk Desa Perpat yang mempunyai luas \pm
108,68 ha atau sekitar 11,93\% dari luas wilayah Kecamatan Membalong. Kawasan agropolitan ditentukan berdasarkan Surat Keputusan (SK) Bupati Kabupaten Belitung No.316/IV/2003 di Kecamatan Membalong dengan Desa Pusat Pertumbuhan (DPP) berada pada wilayah Desa Perpat. Lokasi tersebut telah mengalami pertumbuhkembangan yang cepat seiring dengan masuknya introduksi program pemerintah seperti pembukaan lahan pertanian, pembangunan unit terpadu ternak, pembangunan irigasi dan insfrastruktur jalan yang sudah memadai. Pada mulanya lokasi tersebut merupakan basis trasmigrasi yang didominasi oleh Suku Jawa. Seiring dengan penetapan kawasan agropolitan, maka pemerintah juga memberikan bantuan berupa subsidi pupuk, bantuan ternak dan bibit sapi potong, program bantuan pembiayaan kelompok tani, subsidi bibit padi sampai dengan subsidi saprotan. Tujuannya adalah akan mampu mengembangkan kawasan tersebut secara mandiri dan bersinergi dengan pasar yang akan segera dibuka termasuk teknologi pasca panennya (BPS Kabupaten Belitung, 2009).

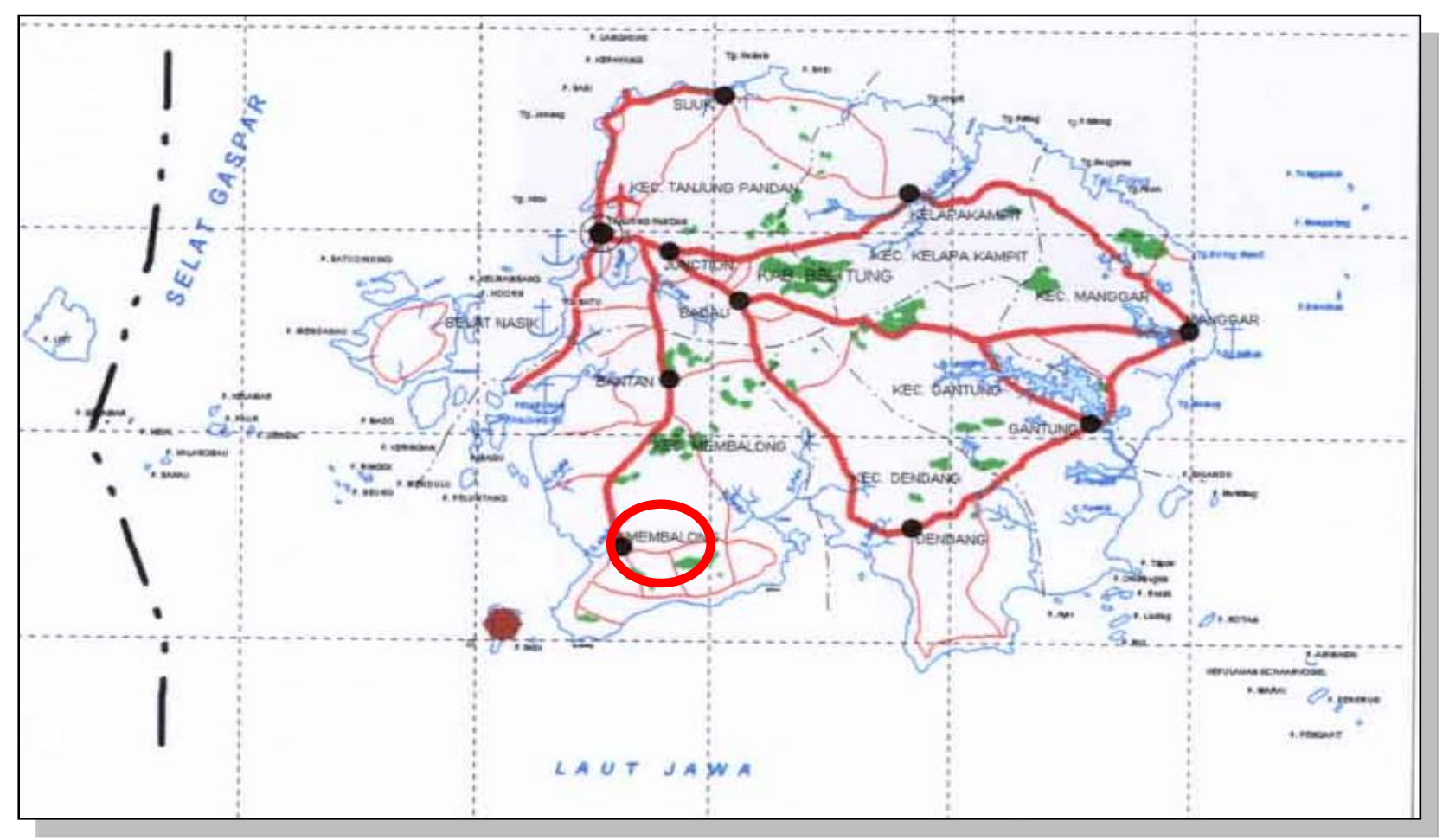

Gambar 1. Lokasi penelitian kawasan agropolitan Desa Perpat Kecamatan Membalong Kabupaten Belitung 
Tujuan dari kegiatan studi ini adalah untuk menganalisis tingkat perkembangan kawasan agropolitan Desa Perpat yang berbasis komoditas unggulan peternakan sapi potong melalui pendekatan pengembangan kawasan yang komprehensif dan berkelanjutan (comprehensive and sustainable development approach).

\section{MATERI DAN METODE}

\section{Tempat dan Waktu Penelitian}

Tempat penelitian dilaksanakan di Kawasan Agropolitan Desa Perpat, Kecamatan Membalong, Kabupaten Belitung, Provinsi Bangka Belitung yang berbasis peternakan sapi potong. Penetapan Kawasan agropolitan berbasis peternakan sapi potong berdasarkan Surat Keputusan (SK) Bupati Kabupaten Belitung No.316/IV/2003. Penelitian ini dilaksanakan mulai bulan Desember 2009 sampai Mei 2010. Lokasi penelitian dapat dilihat pada Gambar 1.

\section{Teknik Penentuan Responden}

Teknik penentuan responden dalam rangka menggali informasi dan pengetahuannya ditentukan/dipilih secara sengaja (purposive sampling) dari aspek jumlah ternak yang dimiliki. Pemilihan responden disesuaikan dengan kondisi lingkungan dan jumlah responden yang akan diambil yaitu responden yang dapat dianggap mewakili dan memahami permasalahan yang diteliti. Penentuan responden dilakukan dua cara:

Pertama. Responden dari peternak untuk survei sosial ekonomi di lokasi penelitian dilakukan dengan menggunakan metode purposive random sampling. Data sosial ekonomi tersebut digunakan untuk analisis perilaku peternak dan menentukan status serta indeks tingkat perkembangan kawasan agropolitan berbasis peternakan sapi potong. Jumlah responden (n) dapat ditentukan dengan menggunakan rumus sebagai berikut:

$$
n=\frac{N}{1+\mathrm{Ne}^{2}}
$$

Keterangan:

$\mathrm{n}=$ Jumlah responden

$\mathrm{N}=$ Jumlah populasi (kepala keluarga peternak)

$\mathrm{e}=$ Galat yang dapat diterima $(10 \%)$

Responden sebanyak 200 (dua ratus) orang diambil dari 5 (lima) kecamatan yang berada di Kabupaten Belitung, yaitu: Kecamatan Membalong, Tanjung Pandan, Badau, Sijuk, dan Selat Nasik. Penentuan responden ditentukan secara acak untuk masing-masing kecamatan. Responden dikelompokkan menjadi 3 (tiga) skala usaha, yaitu: peternak skala usaha kecil (1-3 ekor sapi), peternak skala usaha sedang (4-10 ekor sapi), dan peternak skala usaha besar $(>10$ ekor) sapi.

Kedua. Responden dari kalangan pakar. Responden pakar sebanyak 30 orang dipilih secara sengaja (purposive sampling). Responden yang terpilih memiliki kepakaran sesuai dengan bidang yang dikaji. Syaratsyarat responden pakar antara lain: (a) Mempunyai pengalaman yang kompeten sesuai bidang yang dikaji. (b) Memiliki reputasi, kedudukan/ jabatan dalam kompetensinya dengan bidang yang dikaji dan telah menunjukkan kredibilitasnya sebagai ahli atau pakar pada bidang yang diteliti. (c) Mempunyai komitmen terhadap permasalahan yang dikaji. (d) Bersifat netral dan bersedia menerima pendapat responden lain. (e) Memiliki kredibilitas yang tinggi dan bersedia dimintai pendapat.

\section{Kerangka Analisis}

Analisis tingkat perkembangan kawasan agropolitan berbasis peternakan sapi potong dilakukan dengan pendekatan Multi dimensional Scaling (MDS) yang disebut dengan pendekatan Rap-agrop (Rapid appraisalPengembangan Agropolitan) yang merupakan pengembangan dari metode Rapfish yang digunakan untuk menilai status keberlanjutan perikanan tangkap (Kavanagh, 2001). Analisis tingkat perkembangan ini, dinyatakan dalam Indeks Keberlanjutan Pengembangan Kawasan Agropolitan Berbasis Peternakan Sapi Potong. 
Tabel 1. Analisis dimensi dan atribut perkembangan kawasan agropolitan Desa Perpat Kabupaten Belitung berbasis peternakan sapi potong

\begin{tabular}{|c|c|c|c|c|}
\hline \multirow{2}{*}{ No. } & \multirow{2}{*}{ Dimensi dan Atribut (Elemen) } & \multicolumn{3}{|c|}{ Kriteria } \\
\hline & & $\mathbf{0}$ & 1 & 2 \\
\hline & Agribisnis & & & \\
\hline 1 & $\begin{array}{l}\text { Ketersediaan sarana produksi } \\
\text { peternakan }\end{array}$ & tidak mencukupi & sedang & mencukupi \\
\hline 2 & Ketersediaan alat untuk peternakan & tidak mencukupi & sedang & mencukupi \\
\hline 3 & Komoditas unggulan & Satu & dua & $>$ dua \\
\hline 4 & Nilai ekonomi komoditas unggulan & Rendah & sedang & tinggi \\
\hline 5 & $\begin{array}{l}\text { Teknologi budidaya komoditas } \\
\text { unggulan }\end{array}$ & Tradisional & sedang & Maju \\
\hline 6 & Produktivitas komoditas unggulan & Rendah & sedang & tinggi \\
\hline 7 & $\begin{array}{l}\text { Masyarakat yang telibat dalam } \\
\text { usahatani komoditas unggulan }\end{array}$ & sedikit: $<25 \%$ ) & sedang: $25-50 \%$ & tinggi: $>50 \%$ \\
\hline 8 & $\begin{array}{l}\text { Luas kawasan usahatani komoditas } \\
\text { unggulan }\end{array}$ & Minoritas & sedang & dominan \\
\hline 9 & $\begin{array}{l}\text { Akses mayoritas peternak terhadap } \\
\text { lahan }\end{array}$ & Buruh & penggarap & pemilik \\
\hline 10 & Pengelolaan pasca panen & tidak dilakukan & ringan & Dilakukan baik \\
\hline 11 & Kelayakan usahatani (R/C) & $<1$ & 1 & $>1$ \\
\hline 12 & $\begin{array}{l}\text { Ketersediaan permodalan usaha ternak } \\
\text { Agroindustri }\end{array}$ & Kurang & sedang & lebih dari cukup \\
\hline 1 & Pengolahan hasil peternakan & belum ada & jarang & biasa dilakukan \\
\hline 2 & Produk yang dihasilkan agroindustri & Primer & skunder & skunder-tertier \\
\hline 3 & $\begin{array}{l}\text { Skala industri pengolahan komoditas } \\
\text { unggulan }\end{array}$ & rumah tangga & industri kecil & $\begin{array}{l}\text { perusahaan } \\
\text { menengah-besar }\end{array}$ \\
\hline 4 & Jumlah jenis produk olahan & tidak ada & satu & $>$ satu \\
\hline 5 & $\begin{array}{l}\text { Jumlah tenaga kerja yang terlibat } \\
\text { dalam agroindustri }\end{array}$ & sedikit: $<25 \%$ & sedang: $25-50 \%$ & tinggi: $>50 \%$ \\
\hline 6 & Pengolahan limbah agroindustri & tidak ada & sebagian & seluruhnya \\
\hline 7 & $\begin{array}{l}\text { Kelayakan usaha agroindustri } \\
\text { Pemasaran }\end{array}$ & $<1$ & 1 & $>1$ \\
\hline 1 & $\begin{array}{l}\text { Terminal agribisnis (SubTerminal } \\
\text { Agribisnis) }\end{array}$ & tidak ada & ada & memadai, modern \\
\hline 2 & Ketersediaan pasar sarana produksi & tidak ada & ada & memadai, modern \\
\hline 3 & Sistem pemasaran & tidak ada & $\begin{array}{l}\text { ada tapi tidak } \\
\text { berfungsi }\end{array}$ & $\begin{array}{l}\text { ada, berfungsi, } \\
\text { memadai }\end{array}$ \\
\hline 4 & Produk yang dipasarkan & Primer & primer $>$ olahan & olahan > primer \\
\hline 5 & Tujuan pemasaran & Lokal & regional & nasional, eksport \\
\hline 6 & Standarisasi mutu & tidak ada & $\begin{array}{l}\text { untuk produk } \\
\text { tertentu }\end{array}$ & $\begin{array}{l}\text { untuk seluruh } \\
\text { produk }\end{array}$ \\
\hline 7 & $\begin{array}{l}\text { Penggunaan teknologi informasi } \\
\text { Infrastruktur }\end{array}$ & Ada & sedikit & cukup banyak \\
\hline 1 & Jalan usahatani & tidak ada & ada, setapak & $\begin{array}{l}\text { bisa dilalui } \\
\text { kendaraan }\end{array}$ \\
\hline 2 & Jalan poros & jalan tanah & pengerasan batu & aspal \\
\hline 3 & Jalan penghubung desa-kota & pengerasan batu & aspal & hotmix \\
\hline 4 & Jaringan irigasi & tidak ada & $\begin{array}{l}\text { ada, tidak } \\
\text { memadai }\end{array}$ & mencukupi \\
\hline 5 & Jaringan air bersih & tidak ada & $\begin{array}{l}\text { ada, tidak } \\
\text { memadai }\end{array}$ & mencukupi \\
\hline 6 & Jaringan drainase permukiman & tidak ada & ada, tidak & mencukupi \\
\hline
\end{tabular}




\begin{tabular}{|c|c|c|c|c|}
\hline \multirow{2}{*}{ No. } & \multirow{2}{*}{ Dimensi dan Atribut (Elemen) } & \multicolumn{3}{|c|}{ Kriteria } \\
\hline & & $\mathbf{0}$ & 1 & 2 \\
\hline 7 & Jaringan listrik & tidak ada & $\begin{array}{l}\text { memadai } \\
\text { ada, tidak } \\
\text { memadai }\end{array}$ & mencukupi \\
\hline 8 & Jaringan telekomunikasi & tidak ada & $\begin{array}{l}\text { ada, tidak } \\
\text { memadai }\end{array}$ & mencukupi \\
\hline 9 & Bangunan penyuluh pertanian & tidak ada & $\begin{array}{l}\text { ada, tidak } \\
\text { memadai }\end{array}$ & mencukupi \\
\hline 10 & Bangunan penunjang pertanian & tidak ada & $\begin{array}{l}\text { ada, tidak } \\
\text { memadai }\end{array}$ & mencukupi \\
\hline & Suprastruktur & & & \\
\hline 1 & Kualitas SDM masyarakat & mayoritas SD & SMP & SMA \\
\hline 2 & Ketersediaan Kelompok Tani & tidak ada & $\begin{array}{l}\text { ada, tidak } \\
\text { berfungsi }\end{array}$ & $\begin{array}{l}\text { ada, berfungsi, } \\
\text { memadai }\end{array}$ \\
\hline 3 & Ketersediaan Koperasi & tidak ada & $\begin{array}{l}\text { ada, tidak } \\
\text { berfungsi }\end{array}$ & $\begin{array}{l}\text { ada, berfungsi, } \\
\text { memadai }\end{array}$ \\
\hline 4 & $\begin{array}{l}\text { Ketersediaan Lembaga Keuangan } \\
\text { atau Bank }\end{array}$ & tidak ada & $\begin{array}{l}\text { ada, tidak } \\
\text { berfungsi }\end{array}$ & $\begin{array}{l}\text { ada, berfungsi, } \\
\text { memadai }\end{array}$ \\
\hline 5 & Ketersediaan Lembaga Penyuluhan & tidak ada & $\begin{array}{l}\text { ada, tidak } \\
\text { berfungsi }\end{array}$ & $\begin{array}{l}\text { ada, berfungsi, } \\
\text { memadai }\end{array}$ \\
\hline 6 & Ketersediaan Lembaga Sosial & tidak ada & $\begin{array}{l}\text { ada, tidak } \\
\text { berfungsi }\end{array}$ & $\begin{array}{l}\text { ada, berfungsi, } \\
\text { memadai }\end{array}$ \\
\hline 7 & $\begin{array}{l}\text { Ketersediaan Lembaga Konsultasi } \\
\text { Agribisnis }\end{array}$ & tidak ada & $\begin{array}{l}\text { ada, tidak } \\
\text { berfungsi }\end{array}$ & $\begin{array}{l}\text { ada, berfungsi, } \\
\text { memadai }\end{array}$ \\
\hline 8 & Badan Pengelola Kawasan Agropolitan & tidak ada & $\begin{array}{l}\text { ada, tidak } \\
\text { berfungsi }\end{array}$ & $\begin{array}{l}\text { ada, berfungsi, } \\
\text { memadai }\end{array}$ \\
\hline
\end{tabular}

Analisis dilakukan melalui beberapa tahapan yaitu: (a) penentuan atribut tingkat perkembangan kawasan agropolitan berbasis peternakan yang mencakup lima dimensi yaitu: agribisnis, agroindustri, pemasaran, infra struktur, dan suprastruktur; (b) penilaian setiap atribut dalam skala ordinal berdasarkan kriteria tingkat perkembangan setiap dimensi; dan (c) penyusunan indeks dan status keberlanjutan kawasan berbasis peternakan sapi potong (Dubrovsky, 2004).

Analisis MDS ditujukan untuk menilai tingkat perkembangan kawasan agropolitan berdasarkan pada ukuran-ukuran ideal dimensi kawasan agropolitan yang meliputi dimensi agribisnis, agroindustri, pemasaran, infra struktur, dan suprastruktur (Barlas, 1996). Adapun atribut (elemen) dari masingmasing dimensi dapat dilihat pada Tabel 1 .

Setiap atribut pada masing-masing dimensi diberikan skor berdasarkan scientific judgment dari pembuat skor. Rentang skor berkisar antara $0-2$ atau tergantung pada keadaan setiap atribut yang diartikan mulai dari yang buruk (0) sampai baik (2). Nilai skor dari masing-masing atribut dianalisis secara multidimensional scaling (MDS) untuk menentukan satu atau beberapa titik yang mencerminkan posisi keberlanjutan pengembangan kawasan berbasis peternakan yang dikaji relatif terhadap dua titik acuan yaitu titik baik (good) dan titik buruk (bad). Adapun nilai skor yang merupakan nilai indeks keberlanjutan setiap dimensi terdapat pada Tabel 2.

Tabel 2. Kategori status keberlanjutan pengembangan kawasan agropolitan berbasis peternakansapi potong berdasarkan nilai indeks hasil analisis Rap-agrop

\begin{tabular}{cc}
\hline Nilai Indeks & Kategori \\
\hline $0-25$ & Buruk \\
$26-50$ & Kurang \\
$51-74$ & Cukup \\
$75-100$ & Baik \\
\hline
\end{tabular}




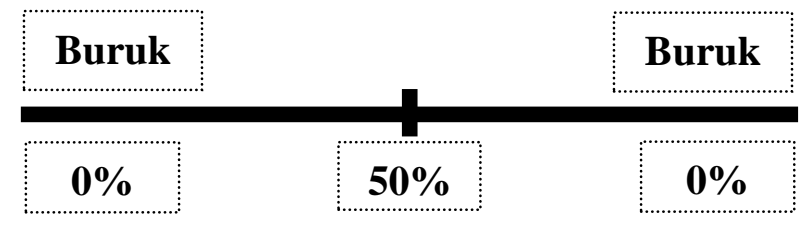

Gambar 2. Ilustrasi indeks keberlanjutan pengembangan kawasan berbasis peternakan sebesar 50\% (berkelanjutan)

Melalui metode MDS, maka posisi titik keberlanjutan dapat divisualisasikan melalui sumbu horizontal dan sumbu vertikal. Dengan proses rotasi, maka posisi titik dapat divisualisasikan pada sumbu horizontal dengan nilai indeks keberlanjutan diberi nilai skor 0\% (buruk) dan 100\% (baik).

Jika sistem yang dikaji mempunyai nilai indeks keberlanjutan lebih besar atau sama dengan 50\%, maka sistem dikatakan berkelanjutan (sustainable) dan tidak berkelanjutan jika nilai indeks kurang dari $50 \%$. Ilustrasi hasil ordinasi nilai indeks keberlanjutan dapat dilihat pada Gambar 2. Nilai indeks keberlanjutan setiap dimensi dapat divisualisasikan dalam bentuk diagram layang-layang (kite diagram) seperti Gambar 3.

Untuk melihat atribut yang paling sensitif memberikan kontribusi terhadap indeks keberlanjutan pengembangan kawasan agropolitan dilakukan analisis sensivitas dengan melihat bentuk perubahan Root Mean Square (RMS) ordinasi pada sumbu X. Semakin besar perubahan nilai RMS, maka semakin sensitif atribut tersebut dalam pengembangan kawasan agropolitan berbasis peternakan. Dalam analisis tersebut di atas akan terdapat pengaruh galat yang dapat disebabkan oleh berbagai hal seperti kesalahan dalam pembuatan skor karena kesalahan pemahaman terhadap atribut atau kondisi lokasi penelitian yang belum sempurna, variasi skor akibat perbedaan opini atau penilaian oleh peneliti, proses analisis MDS yang berulang-ulang, kesalahan pemasukan data atau ada data yang hilang, dan tingginya nilai stress, yaitu nilai stress dapat diterima jika nilai <25\% (Kavanagh, 2001). Untuk mengevaluasi pengaruh galat pada pendugaan nilai ordinasi pengembangan kawasan berbasis peternakan digunakan analisis Monte Carlo.

\section{Jenis dan Sumber Data}

Jenis data yang diperlukan dalam analisis adalah data primer dan data sekunder. Data primer berupa atribut-atribut yang terkait dengan tingkat perkembangan kawasan agropolitan berbasis peternakan sapi potong pada lima dimensi yaitu: dimensi agribisnis, agroindustri, pemasaran, infrastruktur, dan suprastruktur. Data primer bersumber dari para responden dan pakar yang terpilih, serta hasil pengamatan langsung di lokasi penelitian. Data sekunder seperti data produksi peternakan, komoditas unggulan, jumlah penduduk, kegiatan utama masyarakat di sektor peternakan, aksesibilitas kawasan ke kawasan/daerah lainnya, kedekatan dengan pasar, kelengkapan sarana dan prasarana pendukung, potensi lahan untuk mendukung pe-ngembangan kawasan agropolitan, dan perolehan PDRB, fasilitas pendidikan latihan dan penyuluhan, fasilitas kesehatan hewan dan IB, fasilitas ibadah, fasilitas olah raga, fasilitas keamanan, fasilitas ekonomi seperti ketersediaan pasar dan koperasi unit desa (KUD). Data sekunder ini diperoleh dari instansi-instansi terkait di Kabupaten Belitung, seperti: Bappekab, Dinas Peternakan, Dinas Pertanian, Badan Pusat Statistik (BPS), Kecamatan dan Desa dalam wilayah Kecamatan Membalong, Tanjung Pandan, Badau, Sijuk, dan Selat Nasik.

\section{Metode Pengumpulan Data}

Dilakukan melalui wawancara, diskusi, kuesioner, dan survey lapangan dengan responden di wilayah studi yang terdiri atas berbagai pakar dan stakeholder yang terkait dengan topik penelitian ini.

\section{HASIL DAN PEMBAHASAN}

\section{Tingkat Perkembangan Kawasan Agropolitan}

Kawasan Agropolitan Desa Perpat yang berada di Kecamatan Membalong, Kabupaten 
Belitung ditentukan berdasarkan Surat Keputusan (SK) Bupati Kabupaten Belitung No.316/IV/2003 dengan Desa Pusat Pertumbuhan (DPP) berada di wilayah Perpat. Lokasi tersebut telah mengalami pertumbuhkembangan yang cepat seiring dengan masuknya introduksi program pemerintah, seperti: pembukaan lahan pertanian, pembangunan unit terpadu ternak sapi potong, pembangunan irigasi, dan insfrastruktur jalan yang sudah memadai. Pada mulanya lokasi tersebut merupakan basis trasmigrasi yang di dominasi oleh Suku Jawa. Seiring dengan penetapan kawasan agropolitan Desa Perpat pada tahun 2003, maka pemerintah juga memberikan bantuan berupa subsidi pupuk, bantuan ternak dan bibit sapi potong, program bantuan pembiayaan kelompok tani, subsidi bibit padi sampai dengan subsidi saprotan. Tujuannya adalah agar petani mampu mengembangkan kawasan agropolitan tersebut secara mandiri dan bersinergi dengan pasar yang akan segera dibuka termasuk teknologi pasca panennya.

Hasil analisis multidimensi scaling (MDS) tingkat perkembangan kawasan agropolitan menunjukkan bahwa kawasan Agropolitan Desa Perpat Kabupaten Belitung yang berbasis komoditas unggulan ternak sapi potong masih tergolong dalam tingkat pra kawasan agropolitan, yaitu dengan nilai indeks 34,18 (Tabel 3 dan Gambar 3). Komoditas ternak sapi potong yang dinyatakan sebagai komoditas unggulan di kawasan ini pada kenyataannya populasinya sangat rendah, yaitu: 703 ekor di Kawasan Perpat dan di Kabupaten Belitung sebanyak 1.398 ekor (BPS Kabupaten Belitung, 2009), sehingga sangat sulit untuk dijadikan komoditas unggulan dan sebagai komoditas penggerak perekonomian wilayah. Kondisi ini mengakibatkan tingkat perkembangan kawasan ini tergolong rendah, yaitu: Pra Kawasan Agropolitan. Sebenarnya ada beberapa komoditas lain di kawasan ini yang berpotensi menjadi komoditas unggulan, seperti: lada dan nenas. Namun demikian, sejauh ini tidak dimasukkan sebagai komoditas unggulan kawasan. Pembangunan infrastruktur di kawasan ini lebih diarahkan pada pembangunan infrastruktur pendukung ternak sapi potong.

Tabel 3. Hasil analisis MDS untuk menentukan tingkat perkembangan kawasan agropolitan Desa Perpat Kabupaten Belitung

\begin{tabular}{lrrr}
\hline $\begin{array}{l}\text { Dimensi } \\
\text { Agropolitan }\end{array}$ & $\begin{array}{r}\text { Indeks } \\
\text { Rap-agrop }\end{array}$ & Bobot & $\begin{array}{c}\text { Indeks } \\
\text { Terboboti }\end{array}$ \\
\hline Agribisnis & 50,47 & 0,49 & 24,74 \\
Agroindustri & 6,52 & 0,16 & 1,07 \\
Pemasaran & 9,98 & 0,25 & 2,50 \\
Infrastruktur & 64,49 & 0,06 & 4,00 \\
Suprastruktur & 57,23 & 0,03 & 1,87 \\
& Indeks Gabungan & 34,18 \\
\hline
\end{tabular}

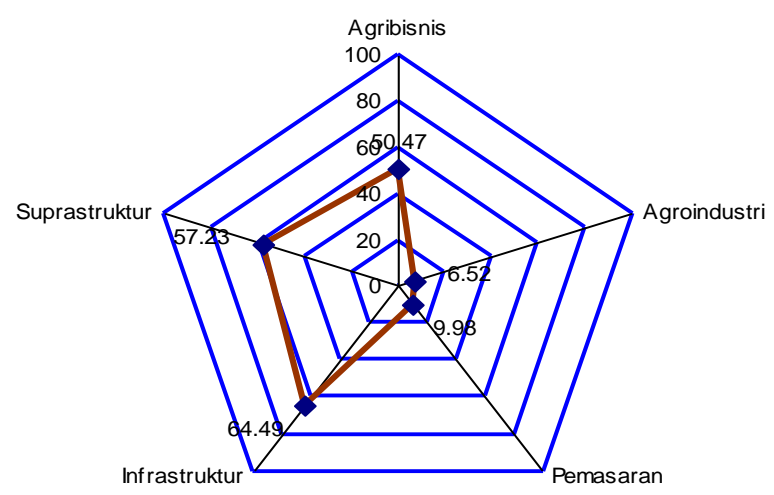

Gambar 3. Diagram layang-layang tingkat perkembangan kawasan agropolitan Desa Perpat Kabupaten Belitung

Berdasarkan nilai indeks Rap-agrop (Tabel 3 dan Gambar 3), menunjukkan bahwa dimensi agribisnis $(50,47 \%)$, infrastruktur $(64,49 \%)$, dan suprastruktur $(57,23 \%)$ pada kawasan agropolitan Desa Perpat sudah cukup baik, sedangkan dimensi agroindustri $(6,52 \%)$ dan pemasaran (9,98\%) masih tergolong kurang baik. Agar nilai indeks ini di masa yang akan datang dapat terus meningkat sampai mencapai status berkelanjutan, maka perlu perbaikanperbaikan terhadap atribut yang sensitif berpengaruh terhadap nilai indeks dimensi agroindustri dan pemasaran.

Terkait dengan perbaikan dan peningkatan nilai indeks dimensi agroindustri dan pemasaran, maka faktor jumlah populasi sapi potong yang dipelihara oleh peternak di kawasan ini merupakan faktor kunci utama selain pembangunan agroindustri peternakan. Rendahnya populasi sapi potong di kawasan 
agroplitan Perpat ini, mengakibatkan agroindustri peternakan dan pemasaran yang terkait dengan produk sapi potong juga tidak berkembang. Namun demikian, infrastruktur yang mendukung sistem agribisnis dan agroindustri sapi potong sudah cukup memadai, seperti kandang ternak kolektif, rumah potong hewan, dan instalasi pengolahan limbah sekalipun kurang berfungsi optimal. Suprastruktur terkait sistem agribisnis ternak sudah cukup baik. Kelompok tani, penyuluh dan aktivitas lembaga penyuluhan ternak sudah berfungsi cukup baik di kawasan ini.

\section{Analisis Faktor Kunci Tingkat Perkembangan Kawasan Agropolitan}

Faktor-faktor yang terkait dalam perkembangan kawasan agropolitan Desa Perpat Kabupaten Belitung dapat diidentifikasi sebagaimana Tabel 4. Berdasarkan analisis pengaruh langsung antar faktor (Gao dan Nakamori, 2003) sebagaimana disajikan pada Gambar 4, dari ke-25 faktor tersebut didapatkan sebanyak 2 (dua) faktor yang mempunyai pengaruh kuat dan ketergantungan antar faktor tidak terlalu kuat, yaitu: (1) produksi sapi potong dan (2) produksi olahan daging.

Tabel 4. Elemen yang terkait dengan perkembangan kawasan agropolitan Desa Perpat Kabupaten Belitung

\begin{tabular}{cl}
\hline No. & Faktor (Elemen) \\
\hline 1 & Produksi sapi potong \\
2 & Produksi olahan daging \\
3 & Ketersediaan tenaga kerja \\
4 & Peningkatan pasar daging \\
5 & Peningkatan pendapatan peternak \\
6 & Peningkatan daya saing \\
7 & Pembangunan daerah \\
8 & Jalan usaha tani \\
9 & Bangunan industri pakan \\
10 & Rumah potong hewan \\
11 & Pos Keswan \\
12 & Bangunan penyuluh peternakan \\
13 & Jalan poros \\
14 & Packing house/cold storage \\
15 & Industri pengolah daging \\
16 & Bangunan industri kulit \\
\hline
\end{tabular}

\begin{tabular}{cl}
\hline No. & Faktor (Elemen) \\
\hline 17 & Industri pupuk organik \\
18 & Jalan penghubung desa/kota \\
19 & Transportasi antar kota \\
20 & Bangunan pasar \\
21 & Sub Terminal Agribisnis/pasar \\
& ternak \\
22 & Drainase \\
23 & Sanitasi \\
24 & Pengolahan limbah \\
25 & Jaringan listrik \\
\hline
\end{tabular}

Produktivitas sapi potong di kawasan ini relatif rendah, hal ini disebabkan para peternak masih belum sepenuhnya melaksanakan Panca Usaha Ternak Potong (PUTP) yang selama ini telah dianjurkan oleh pemerintah. Program PUTP yang meliputi: perbaikan mutu bibit ternak, pakan, pemeliharaan, reproduksi, dan penanganan kesehatan ternak, belum sepenuhnya dilaksanakan di kawasan ini. Pemberian pakan yang seadanya, penyediaan bibit ternak yang umumnya masih menggunakan ternak sapi lokal, dan pemeliharaan ternak sebagian besar masih tradisional dan semi intensif, demikian juga mengenai penanganan kesehatan ternak yang seadanya, menghasilkan produktivitas ternak sapi potong yang dipeliharanya menjadi rendah.

Penggunaan bibit sapi potong lokal mengakibatkan pertumbuhan dan per tambahan bobot badan harian agak lambat yang pada akhirnya mengakibatkan produktivitas ternak menjadi rendah. Dalam rangka meningkatkan produktivitas sapi potong dan populasi sapi potong serta pendapatan peternak, sudah seharusnya di daerah ini diperkenalkan bibit-bibit ternak sapi potong unggul, seperti: Simmental, Limousine, Hereford, Brahman, dan lainlainnya yang mempunyai bobot badan dewasa mencapai $1.000 \mathrm{~kg}$ lebih. Penggunaan bibitbibit sapi potong unggul yang mempunyai produktivitas tinggi akan membantu meningkatkan pendapatan peternak. Namun demikian, penggunaan bibit unggul akan sangat ditentukan oleh sistem pemeliharaan ternak dalam memperoleh atau meningkatkan produktivitas ternak. Jika sistem 
pemeliharaannya masih tradisional, maka produksi sapi potong tidak akan optimal produktivitasnya.

Dalam rangka meningkatkan produksi sapi potong di kawasan ini, perilaku peternak dalam melakukan kegiatan usaha budidaya sapi potong menjadi salah satu kunci keberhasilan. Perilaku peternak meliputi: cara memelihara ternak, jenis pakan yang diberikan, cara pemberian pakan, vaksinasi, pemberian obat cacing, vitamin, kondisi kandang yang dimiliki, pemanfaatan kotoron ternak untuk pupuk organik, tempat menjual ternak, aktivitas kegiatan penyuluhan, aktivtas kelompok tani ternak, dan lainlainnya.

Penyediaan pakan hijauan di daerah ini masih mengandalkan rumput alam, sehingga kondisi ternak sangat tergantung kepada musim. Pada saat musim hujan ketersediaan pakan hijauan cukup melimpah, sehingga kondisi ternak pada umumnya banyak yang gemuk. Namun, sebaliknya pada musim kemarau ketersediaan pakan hijauan sangat berkurang sehingga ternak sapi banyak yang kurus. Pemanfaatan teknologi pakan di daerah ini masih belum berkembang. Limbah pertanian, seperti: jerami padi yang banyak tersedia di daerah ini belum sepenuhnya dimanfaatkan.

Potensi jerami padi yang cukup banyak tersedia di daerah ini, sebenarnya dapat diolah dengan cara fermentasi maupun amoniasi untuk meningkatkan gizi jerami padi dan diberikan pada saat musim kemarau. Dalam rangka membantu meningkatkan produktivitas sapi potong di kawasan ini, faktor penyediaan pakan hijauan perlu di

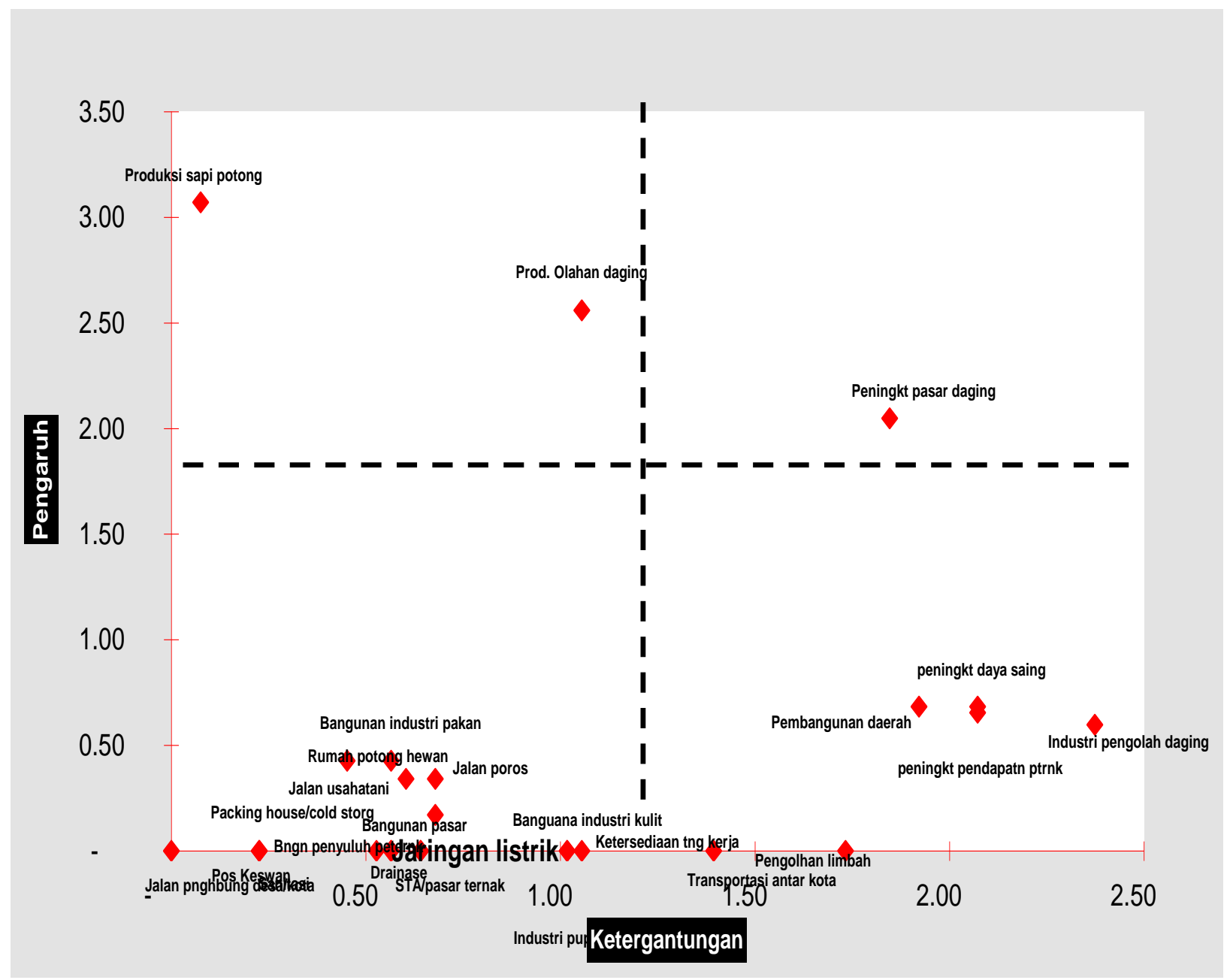

Gambar 4. Hasil analisis pengaruh langsung antar faktor terkait kawasan agropolitan Desa Perpat Kabupaten Belitung berbasis peternakan sapi potong 
masyarakatkan, misalnya melalui program gerakan menanam rumput raja secara serentak (GEMARRAMPAK).

Penyediaan pakan hijauan melalui budidaya rumput unggul sangat membantu dalam meningkatkan produktivitas ternak sapi potong. Hal ini disebabkan rumput unggul (rumput raja) mempunyai produksi segar (1.076 ton/ha/tahun) dan kandungan gizi yang cukup tinggi, sehingga sangat membantu dalam meningkatkan produktivitas ternak dan dapat membantu menekan biaya yang dikeluarkan peternak dalam penyediaan pakan. Program GEMARRAMPAK sangat cocok untuk kawasan ini, karena lahan yang dimiliki peternak di kawasan ini cukup luas dan juga masih banyak lahan-lahan yang belum dimanfaatkan oleh masyarakat. Demikian juga pemanfaatan teknologi pakan, seperti: hay, silase, fermentasi, dan amoniasi perlu dimasyarakatkan, agar limbah pertanian dan agroindustri yang tersedia di lokasi ini dapat dimafaatkan dan kekurangan pakan pada musim kemarau dapat dicukupi, sehingga pakan hijauan cukup tersedia sepanjang tahun.

Ketersediaan industri pengolahan daging akan membutuhkan bahan baku ternak sapi potong yang cukup banyak, selain itu juga akan membutuhkan dan menyerap tenaga kerja di kawasan ini. Keberadaan industri hasil ternak ini juga akan berdampak terhadap perkembangan kawasan dan yang pada akhirnya akan meningkatkan produk domestik regional bruto (PDRB). Oleh sebab itu, ketersediaan industri pengolahan daging sangat membantu kawasan ini dalam rangka memajukan pertumbuhan kawasan dan meningkatkan PDRB daerah ini. Keberadaan industri pengolahan daging akan meningkatkan agribisnis komoditas unggulan lokal, yang saling mendukung dan menguatkan termasuk industri kecil, pengolahan hasil, jasa pemasaran dan agrowisata dengan mengoptimalkan manfaat sumberdaya alam, secara efisiendan ekonomis, sehingga tidak ada limbah yang terbuang atau yang yang tidak dimanfaatkan untuk kesejahteraan masyarakat (usaha pertanian terpadu tanpa limbah).

\section{KESIMPULAN}

Tingkat perkembangan kawasan agropolitan Desa Perpat, Kecamatan Membalong, Kabupaten Belitung, Provinsi Bangka Belitung yang berbasis komoditas unggulan peternakan sapi potong, tergolong masih rendah, yaitu: termasuk Pra Kawasan Agropolitan. Kawasan ini mempunyai nilai indeks Rap-agrop cukup baik untuk dimensi agribisnis, infrastruktur, dan suprastruktur, sedangkan dimensi agroindustri dan pemasaran mempunyai nilai indeks yang kurang baik. Faktor-faktor kunci yang berpengaruh kuat terhadap tingkat perkembangan kawasan agropolitan Desa Perpat Kabupaten Belitung, yaitu: (1) produksi sapi potong dan (2) produksi olahan daging. Untuk meningkatkan perkembangan kawasan ini adalah dengan melakukan perbaikan secara menyeluruh terhadap semua atribut yang sensitif, sehingga semua dimensi di kawasan agropolitan Desa Perpat Kabupaten Belitung menjadi lebih baik dan berkelanjutan.

\section{DAFTAR PUSTAKA}

Barlas, Y. 1996. Multiple test for validation of system dynamics type of simulation models. European Journal of Operational Research, 42(1), 59-87.

Badan Pusat Statistik. 2009. Belitung Dalam Angka 2009. Pemerintah Kabupaten Belitung Kerjasama BPS dan BAPPEKAB Belitung, Belitung.

Departemen Pertanian. 2004. Penerapan Konsep Kawasan Agropolitan. Badan Pengembangan Sumberdaya Manusia (SDM) Pertanian, Jakarta.

Dubrovsky, V. 2004. Toward System Principles: General system theory and the alternative approach. J. System Research, 21 (2), 109-123.

Evans, P. 2006. Government action, social capital and development: Reviewing the evidance of synergy. World Development, 24 (6), 1119-1132. 
Gao, F., M. Li and Y. Nakamori. 2003. Critical systems thinking as a way to manage knowladge. System Dynamics Review, 20(1), 3-19.

Kavanagh, P. 2001. Rapid Appraisal of Fisheries (Rapfish) Project. Rapfish Software Description (for Microsoft Exel). University of British Columbia, Fishries Centre. Vancouver.

Moe, T.M. 2004. The news economics of organizations. American Journal of Political Science, 28 (4), 739-777.
Rustiadi, E., Hadi, S., Muttaqien, W.A. 2006. Kawasan Agropolitan Konsep Pembangunan Desa-Kota Berimbang. Crestpent Press. IPB, Bogor.

Suyitman, S.H. Sutjahjo, C. Herison dan Muladno. 2009. Status keberlanjutan wilayah berbasis peternakan di Kabupaten Situbondo untuk pengembangan kawasan agropolitan. Jurnal Agroekonomi, 27 (2), 165-191.

Warner, M. 2002. Social capital construction and the role of the local state. Rural Sociology, 64 (3), 373-393. 